\title{
THE NATIONAL RESEARCH DEVELOPMENT CORPORATION
}

$\mathrm{T}$ HE fifteenth annual report of the National Research Development Corporation* covers the year ended June 30,1964 , in which there was a striking increase in business transacted. More than 30 new development projects, representing an initial investment of $\$ 85,000$, were undertaken, compared with 12 in the previous year, and 71 licence agreements with industry were completed, compared with 45 .

Of 934 inventions communicated to the Corporation during the year, 287 were from Government Departments and Research Councils, 125 from universities, 2 from nationalized industries, 6 from industrial research associations and $\mathbf{4 5 8}$ from private firms and individuals in the United Kingdom. Of 184 patent rights assigned to the Corporation during the year, 110 were from Government departments and Research Councils and 59 from universities. At the end of the year the Corporation held 399 United Kingdom patent applications and 599 granted patents as well as 935 overseas patent applications and 1,277 granted patents. A further 108 United Kingdom patent applications and granted patents were held by the Corporation's subsidiary development companies, as well as 790 overseas patent applications and granted patents. Besides the $7 \mathrm{I}$ licence agreements completed in the United Kingdom during the year, 561 such agreements were in force and 1,170 United Kingdom patents and patent applications are the subject of exploitation. Present-day development projects at the end of the year number 60 . Six projects, on which $£ 172,689$ had been expended, were discontinued. External expenditure on development was $\$ 457,366$ with forward contractual commitments totalling $£ 1,365,000$.

The range of new projects, a third of which are joint ventures with industry, is illustrated by their descriptive

* National Research Development Corporation. Report and Statement of Accounts for the year July 1, 1963, to June 30, 1964. Pp. 31. (London:
H.M.S.O., 1964.) $2 s, 3 d$. net. titles: actinonin (an antibiotic); air warehouse for the tropics; anti-coagulant from snake venom; attenuation of radiation; automatic foundry plant; automatic racking and packing equipment; averaging computer; cheese curd torsimeter; detection of foreign bodies in milk bottles; Diesel engine development; differential thermal analysis equipment; fish finder; floating breakwater; granular separator; grassland reseeding machine; hydrostatic transmission (Metal Industry Research Association Gear); incontinence device; photo-typesetters; salmonellosis vaccines; two-speed single-winding induction motor; and vegetable harvester. Of existing projects the develop. ment of the hovercraft remains the largest in terms of financial and administrative assistance, while the antibiotic cephalosporin $C$ continues to show promise. Work on the automatic oil-well drilling rig was delayed by fire.

Cumulative investment in external expenditure on

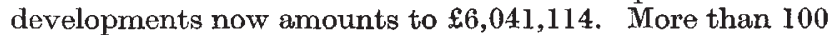
potential projects were still under consideration at the end of the year, and the Corporation continued its investigations concerning a basis for decisions as to whether programmes of work should be supported to meet identified targets in civil, chemical and cryogenic engineering, and the mechanical aspects of the solid-state sciences. Under contract from the Department of Scientific and Industrial Research, a study was undertaken of the implications for economic growth of the results of research on new materials. Discussions also continued with industry and with the Department of Technical Co-operation, the Tropical Products Institute, the Pest Infestation Laboratory, and the National Institute of Agricultural Engineering about projects which would benefit the underdeveloped territories as users and the United Kingdom as manufacturer, initially at least, of equipment derived from development work.

\section{FOREST GENETICS AND TREE IMPROVEMENT}

$I^{\mathrm{N}}$ August 1963 a World Consultation on Forest Genetics and Tree Improvement was held in Sweden, and this must count as an important meeting for all tree geneticists and also for all those in any way concerned with afforestation and reforestation work. The Proceedings, with more than 100 papers, have been published by the Food and Agriculture Organization, but a special double issue of UNASYLVA (18 (2-3), Nos. 73-74. Rome: Forestry and Forest Products Division, Food and Agriculture Organization, 1964) is devoted to the recommendations made and to eleven articles which were revised and rewritten by their authors to incorporate the results of the discussions which took place in Sweden.

It can truly be said that these articles range very well over the subject of tree geneties and their scientific value and literary style are extremoly good. They include chapters on cytogenetics, population genetics, hybridization between species and races, provenance research, seed production and seed certification. A suggestion made by one author is that research on the improvement of exotic trees should be carried out both in the country of origin and in the country of planting. Surprise is expressed that so little attention has been directed to the physiology of root growth in trees in view of the great practical importance of this subject. Two interesting chapters on breeding for resistance to disease and to insect attack end with pleas for international co-operation so that real progress may be made. Great skill has been used to present these subjects in such concise fashion and to show the reader what has been achieved and what is needed. Each article is well supported with appropriate references.

In meeting the request of the Director of the Forestry and Forest Products Division of the Food and Agriculture Organization to propose a programme to co-ordinate the development and spread of knowledge concerning forest genetics and tree improvement the participants at the Consultation addressed a series of recommendations to Governments and jointly to the Food and Agriculture Organization of the United Nations and to the International Union of Forest Research Organizations. Those addressed to Governments point out the great urgency for developing planned programmes of forest genetics and tree improvement in tropical countries, the noed to include forest genetics as a subject in forestry education at all levels, the importance of directing attention to seed sources and provenance trials in countries concerned with afforestation and reforestation, the advisability of estab- 